\title{
Circular RNA, a novel marker for cancer determination (Review)
}

\author{
YINJIE SU, GUANGZHENG ZHONG, NING JIANG, MING HUANG and TIANXIN LIN
}

Department of Urology, Sun Yat-Sen Memorial Hospital, Sun Yat-Sen University, Guangzhou, Guangdong 510120, P.R. China

Received March 2, 2018; Accepted July 5, 2018

DOI: $10.3892 /$ ijmm.2018.3795

\begin{abstract}
Circular RNAs are abundant and conserved endogenous RNAs that are formed by exon skipping or back-splicing events and occur in all forms of life. They have been proven to exhibit tissue- or cell-type specificity and to be able to regulate cell behavior through multiple pathways. In cancer research, numerous studies have indicated that circular RNAs serve as potential biomarkers and therapeutic targets. Furthermore, differential expression of certain circular RNAs clearly predicts the clinical outcomes of cancer patients. Circular RNAs regulate carcinogenesis and cancer progression by acting as a microRNA sponge, coding for proteins and interacting with proteins. The present review mainly focuses on the recent literature regarding the role of circular RNAs in cancer, which may suggest novel strategies for cancer prognosis, diagnosis and clinical treatment.
\end{abstract}

\section{Contents}

1. Introduction

2. Biogenesis of circular RNAs

3. Function of circular RNAs in cancer

4. Circular RNAs as potential biomarkers in cancer

5. Perspectives

\section{Introduction}

Genomic expression and regulation depends on the canonical cooperation of coding and non-coding genes. Aberrant activity of either directly leads to biological dysfunction or even to disease, e.g. cancer. Considering the processes of carcinogenesis, numerous mechanisms are capable of regulating cancer development. Among them, non-coding RNA has been gradually recognized over the past few decades as

Correspondence to: Dr Tianxin Lin, Department of Urology, Sun Yat-Sen Memorial Hospital, Sun Yat-Sen University, 107 West Yanjiang Road, Guangzhou, Guangdong 510120, P.R. China

E-mail: tianxinl@sina.com

Key words: circular RNA, cancer, diagnosis, biomarker, therapeutic target having a significant role in cancer (1). In contrast to the genes that code for proteins, non-coding RNA may regulate gene expression during or after transcription as well as during translation. Sharing common features with non-coding RNA, circular RNA has recently been identified as a novel marker for cancer (2).

Circular RNAs are a large class of endogenous RNA occurring in all forms of life, including eukaryotes, prokaryotes, microbes and viruses. Circular RNA is a type of RNA that is formed by exon skipping or back-splicing events $(3,4)$. Unlike the well-known linear RNA, circular RNA is formed with a covalently closed loop. This loop is formed by binding between the $3^{\prime}$ and $5^{\prime}$ ends in an RNA molecule. This circular feature confers multiple properties to circular RNAs, several of which have only been recently identified. In eukaryotic cells, circular RNA was first identified in the cytoplasm by using electron microscopy in 1979 by Hsu and Coca-Prados (5). However, this observation attracted little attention at the time, as the circular RNA form was assumed to be a type of transcriptional junk produced by mRNA splicing. In the early 1990s, circular RNA was observed in higher eukaryotic cells (6). It was identified that the DCC netrin 1 receptor, a tumor suppressor gene, was transcribed into a lower expression of the non-polyadenylated component of cytoplasmic RNA. In addition, this transcript was indicated to be formed by exons joining accurately at a consensus splice site in human cells. Nigro et al (6) put forward the term 'exon scrambling' for the first time, which means that RNA splicing does not always follow the order predicted from the positions of exons in the genome but may be spliced at any position once there is a consensus splice site. Since then, an increasing number of circular RNAs have been identified in eukaryotic cells, with the mouse sex-determining region $\mathrm{Y}$ (SRY) gene being one of the most commonly reported genes (7). SRY is a gene for male determination with only one intron. During mouse development, SRY genes may be translated into protein whilst keeping their linear form, and in mature testes, the reverse sequence located on the 2 sides of the SRY genes enable the circularization of SRY, which is then stored with a non-coding pattern in the cytoplasm.

With the wide use of high-throughput RNA-sequencing technology and bioinformatics tools, an increasing number of circular RNAs have been identified and characterized. Thus, the stable expression of this RNA type in cells people has been increasingly recognized and research now focuses on its role in controlling or regulating physical and pathological processes. It has been identified that circular RNA mainly exists in the cytoplasm and that most circular RNAs are 
derived from exons, with only a few are generated from introns. In 2012, Salzman et al (8) started to develop an algorithm in pediatric acute lymphoblastic leukemia patients via using high-throughput RNA sequencing. They identified 1,232 genes that were transcribed with exon scrambling. In addition, those identified gene transcripts were also identified in peripheral blood samples of patients, which further supported the general feature of circular RNA expression patterns in human cells. Of note, this group also identified that the expression of circular RNA is highly evolutionarily conserved, although the circular RNA expressed varies among different cell types or species. In addition, circular RNA expression profiles, the ratio between circular and linear RNA and the pattern of spliced isoforms is cell-specific (9). Later, Jeck and Sharpless (4) and Jeck et al (10) identified $>25,000$ circular isoforms that are transcribed from $14 \%$ of the actively expressed genes in fibroblasts. Due to the RNA splicing pattern, one heterogeneous nuclear RNA may be spliced into numerous circular isoforms. Due to the lack of 5' and 3' ends, circular RNAs are more resistant to exonuclease-mediated degradation and are more stable than most linear RNAs in cells. Hence, the circular RNAs are theoretically expressed at higher levels than their associated linear RNAs. The abundance of circular RNA has been reported to be $>10$-fold of that of the associated linear RNA $(4,10)$. These results indicate that circular RNAs may serve as novel biomarkers for various diseases.

The cell is the basic unit of life. While cell behavior relies on reasonable genomic control, aberrant gene regulation directly leads to cellular disorder. Cancer is a disease of genomic instability. While numerous treatments are available, cancer is a disease class comprising a cell system with dynamic genomic changes and the ability to evade immune surveillance, which enables cancer to survive. In addition, this system may evolutionarily evolve in order to sustain and progress its malignant phenotype. Circular RNA has been indicated to be involved in numerous types of cancer. Circular RNA is highly stable and evolutionarily conserved. Regarding cancer, numerous studies have reported that circular RNA may be differentially spatiotemporally expressed according to the different status of cells. High-throughput RNA sequencing suggested that a variety of circular RNAs are significantly dysregulated in cancer tissues when compared with those in adjacent tissues. For instance, circHIPK3 expression is decreased by $\sim 79.5 \%$ in bladder cancer tissues when compared with that in normal bladder tissues (11). Furthermore, circMTO1 expression was decreased by $87.4 \%$ in hepatocellular carcinoma tissue compared with that in matching non-tumorous tissues (12). At the same time, the level of circHIPK3 in bladder cancer patients and that of circMTO1 in hepatocellular carcinoma patients was highly correlated with the pathological stage and prognosis. In addition, it has been determined that circular RNAs are more abundant in exosomes than in cells, which suggests that circular RNAs may serve as promising cancer biomarkers (13). Li et al (14) identified >1,000 circular RNAs in human serum exosomes. Circular RNAs originating from human cancer cells may enter the circulation via participating in exosome packing, which may be readily measured. Of note, those circRNAs measured in exosomes may be used to differentiate between colon cancer patients and healthy individuals. In addition, several studies have proven that circular RNAs may be used as biomarkers in cancer $(2,15-17)$. It is therefore indicated that circular RNAs may be used as biomarkers in cancer diagnosis and prognosis. Furthermore, several circular RNAs have been proven to be ultimately important in controlling cancer cell fate, e.g. overexpressed ciRS-7, which promotes colon cancer carcinogenesis via activating the epidermal growth factor receptor/RAF1/mitogen-activated protein kinase pathway $(18,19)$, while circMYLK promotes bladder cancer progression through modulation of the vascular endothelial growth factor A (VEGFA)/VEGF receptor 2 (VEGFR2) signaling pathway (20). These results suggest that certain circular RNAs may be regarded as potential therapeutic targets in cancer. Hence, the present review not only focused on the role of circular RNA as a biomarker in cancer but also discussed its biological roles in cancer.

\section{Biogenesis of circular RNAs}

Compared with the prokaryotic genes, eukaryotic genes are split by a series of non-coding sequences known as introns. In eukaryotes, when the gene is transcribed from DNA into mature mRNA, the introns are removed, leaving just the exons in the mature mRNA. Subsequently, the remaining exons are translated into proteins (21). The intron removal procedure during this process is known as canonical splicing. With the discovery of circular RNA, it has become apparent that it may be formed via gene splicing, but in a non-canonical way. During non-canonical splicing, circular RNA is synthesized by canonical splicing combined with back-splicing $(22,23)$.

Similar to linear RNA, circular RNA is also derived from pre-mRNA. The actual mechanisms of its biogenesis are presented in Fig. 1. According to the constituent sections, circular RNA may be classified into four types, including exonic circular RNA, intronic circular RNA, exon-intron circular RNA and tRNA intronic circular RNA (22). During pre-mRNA splicing, RNA binding proteins or the ALU reverse complementary sequence bridge the two flanking introns, joining them together and allowing the downstream $5^{\prime}$ end (the splice donor) to be connected to the upstream $3^{\prime}$ end (the splice acceptor) $(10,24,25)$. Later, by back-splicing in combination with canonical splicing, the exonic circular RNA is formed. Furthermore, if only back-splicing occurs with an intron retained, an exon-intron circular RNA is generated. In addition, exonic and exon-intron circular RNA may also be generated by exon skipping (25). A partially folded pre-mRNA brings the original and non-adjacent exon close to another exon. Subsequently, exon skipping occurs, during which flanking regions (containing ALU paring) at the ends of the 2 exons are joined by canonical splicing, thus forming exonic circular RNA. Similarly, if an intron is still retained, exon-intron circular RNA is generated. Intronic circular RNA is derived from the lariat intron that is excised from pre-mRNA by the canonical splicing machinery (26). The excised lariat intron containing a 7-nt GU-rich element near the 5' splice site and an 11-nt C-rich element near the $3^{\prime}$ tail of the branchpoint site may undergo circularization. While this structure enables the formation of intronic circular RNA, it also helps the excised lariat intron to escape debranching and exonucleolytic degradation. tRNA intronic circular RNAs are generated from the excised tRNA introns that are removed by tRNA splicing 


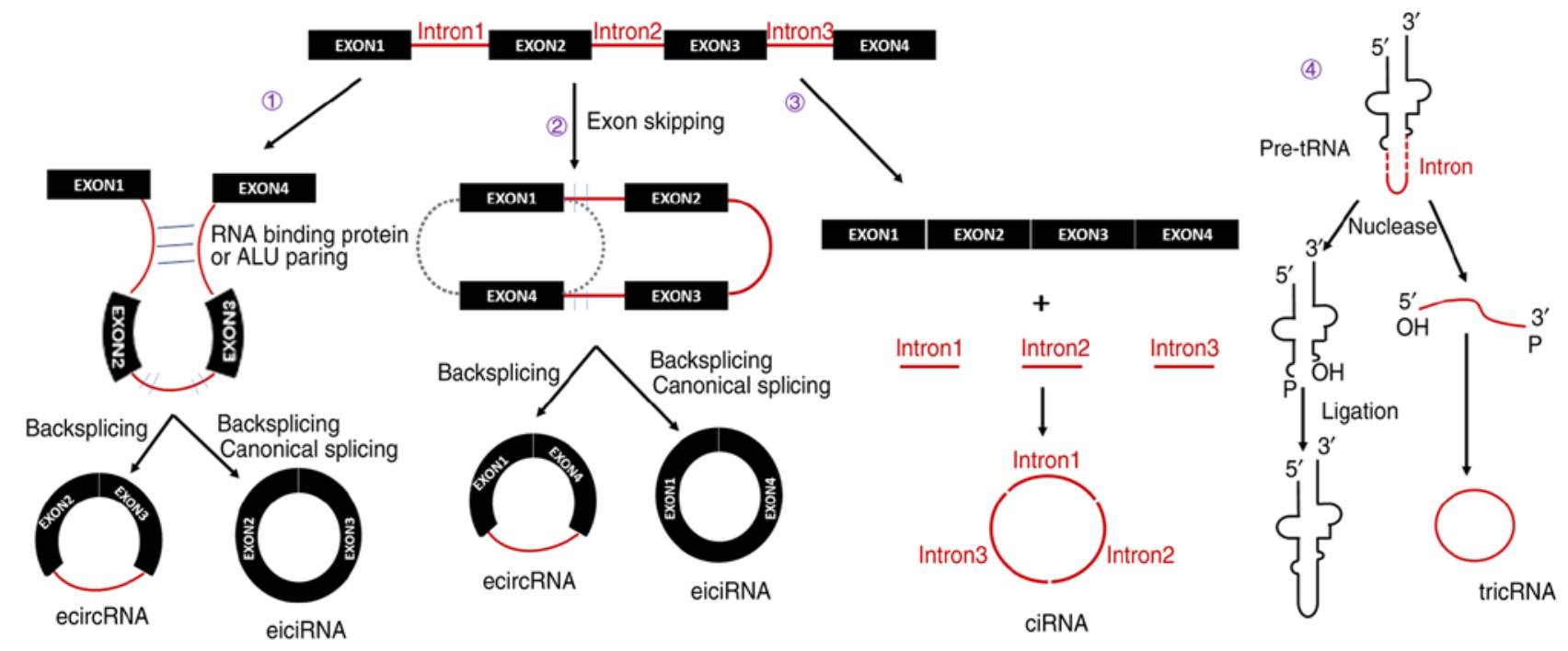

ALU paring

Figure 1. Biogenesis of circular RNA. Circular RNA may be classified into four types: EcircRNA, ciRNA, eiciRNA and tricRNA. Furthermore, there are four mechanisms of circular RNA biogenesis: i) In pre-mRNA splicing, RNA-binding proteins or the ALU reverse complementary sequence bridge the two flanking introns and join them together, which allows the downstream 5' end to be connected to the upstream 3 ' end. ii) A partially folded pre-mRNA brings flanking regions (contains ALU paring) of the original and non-adjacent exon close to another exon. Subsequently, exon skipping occurs to join the ends of the 2 exons. iii) ciRNA is derived from the lariat intron that is excised from pre-mRNA by the canonical splicing machinery. iv) tricRNA are generated from the excised tRNA introns that are removed by tRNA splicing enzymes. The 3',5'-phosphodiester linkage between the two termini of those excised tRNA introns generates the tricRNA. ecircRNA, exonic circular RNA; ciRNA, intronic circular RNA; exon-intron circular RNA, eiciRNA; tricRNA, tRNA intronic circular RNA.

enzymes (27). The 3',5'-phosphodiester linkage between the two termini of those excised tRNA introns generates the tRNA intronic circular RNA.

\section{Function of circular RNAs in cancer}

Hundreds of thousands of circular RNAs have been identified through the widespread use of high-throughput RNA-sequencing technology. As mentioned above, endogenous circular RNAs may be classified into 4 types, and each type has different functions to regulate gene expression. In general, the functions may be divided into 4 categories: Protein binding, microRNA sponging, and regulation of transcription and protein translation. Among the four types of circular RNA, those with exons mainly exist in the cytoplasm, where they exert post-transcriptional and translational effects, while circular RNAs with introns are predominantly retained in the nucleus, where they regulate gene transcription and splicing. In this chapter, the role of circular RNA in cancer with regard to the different functions of circular RNA is highlighted (Table I).

Circular RNA sequesters micro (mi)RNA to regulate cancer cells. miRNAs are small non-coding RNAs of $\sim 21 \mathrm{nt}$ in length. They repress the translation of mRNA via directly targeting their 3'-untranslated region by base-pairing and then triggering mRNA cleavage, relying on the degree of complementarity. It has been identified that circular RNA contains a region with a miRNA response element, which may act as competing endogenous RNA to reduce the binding between miRNA and target genes. The first sponge circular RNA to be characterized was ciRS-7. It was determined that ciRS-7 shares $>73$ binding sites with miRNA-7 (28). Their binding strongly decreased the suppression of the downstream genes of miRNA-7. Ectopic expression of ciRS-7 significantly mimics the phenotype of miRNA-7 knockdown. Therefore, it has been suggested that circular RNA may serve as a miRNA antagonist or miRNA sponge. Since then, an increasing number of circular RNA have been identified as having roles as miRNA sponges, including circHIPK3, which has been observed to bind to 9 miRNAs with 18 potential binding sites. Silencing of circHIPK 3 but not HIPK3 mRNA significantly inhibits human cell growth (29). It may be concluded that recent evidence supports that circular RNA regulates various processes in cancer cells via sponging of miRNAs.

The abovementioned miRNA-7 is a well-known tumor suppressor, while ciRS-7 is able to act as a sponge for miRNA-7 and impair the tumor suppressive role of miRNA-7. In gastric cancer, it has been identified that miRNA-7-induced tumor suppression in MGC-803 and HGC-27 cells may be blocked by ciRS-7, leading to a more aggressive oncogenic phenotype via antagonizing the inactivation of miRNA-7 mediated by the phosphatase and tensin homologue (PTEN)/phosphoinositide-3 kinase (PI3K)/AKT pathway (30). CircPVT1 is a transcript that is derived from the PVT1 gene. It is upregulated in gastric cancer tissue. Chen et al (31) reported that this transcript may promote cell proliferation by acting as a sponge for members of the miRNA-125 family. CircLARP4 was identified to suppress the proliferation and invasion of gastric cancer cells. It has been indicated that circLARP4 may act as a sponge for miRNA-424-5p, which usually targets the large tumor suppressor kinase 1, a core part of the Hippo signaling pathway, which functions as a tumor suppressor in gastric cancer (32). 
Table I. Potential circular RNAs in cancer therapy and determination of their functions and roles.

\begin{tabular}{|c|c|c|c|c|c|}
\hline Circular RNA & Cancer type & Dysregulation & Action & Role & (Refs.) \\
\hline ciRS-7 & Gastric cancer & Upregulated & Sponge for miR-7 & Oncogene & (30) \\
\hline circPVT1 & Gastric cancer & Downregulated & Sponge for miR-125 & $\begin{array}{l}\text { Inhibits invasion, migration } \\
\text { and angiogenesis }\end{array}$ & $(31)$ \\
\hline circLARP4 & Gastric cancer & Downregulated & Sponge for miR-425-5p & $\begin{array}{l}\text { Suppresses migration and } \\
\text { growth }\end{array}$ & $(32)$ \\
\hline hsa_circ_0006528 & Breast cancer & Downregulated & Sponge for miR-7-5p & Drug resistance & (33) \\
\hline $\operatorname{circABCB} 10$ & Breast cancer & Upregulated & Sponge for miR-1271 & $\begin{array}{l}\text { Promotes proliferation and } \\
\text { suppresses apoptosis }\end{array}$ & (34) \\
\hline circTCF25 & Bladder cancer & Upregulated & $\begin{array}{l}\text { Sponge for } \\
\text { miR-103a-3p/miR-107 }\end{array}$ & $\begin{array}{l}\text { Promotes proliferation and } \\
\text { migration }\end{array}$ & $(35)$ \\
\hline circHIPK3 & Bladder cancer & Downregulated & Sponge for miR-558 & $\begin{array}{l}\text { Inhibits invasion, migration, } \\
\text { and angiogenesis }\end{array}$ & $(11)$ \\
\hline circMYLK & Bladder cancer & Upregulated & Sponge for miR-29a & $\begin{array}{l}\text { Promotes tumor growth and } \\
\text { metastasis }\end{array}$ & (20) \\
\hline hsa_circ_0001564 & Osteosarcoma & Upregulated & Sponge for miR-29c-3p & Promotes tumorigenicity & (36) \\
\hline hsa_circ_0016347 & Osteosarcoma & Upregulated & Sponge for miR-214 & $\begin{array}{l}\text { Promotes proliferation, } \\
\text { invasion and metastasis }\end{array}$ & (37) \\
\hline circUBAP2 & Osteosarcoma & Upregulated & Sponge for miR-2143 & $\begin{array}{l}\text { Promotes growth and inhibit } \\
\text { apoptosis }\end{array}$ & $(38)$ \\
\hline circGLI2 & Osteosarcoma & Upregulated & Sponge for miR-125b-5p & $\begin{array}{l}\text { Promotes proliferation, } \\
\text { migration and invasion }\end{array}$ & (39) \\
\hline hsa_circ_0005986 & $\begin{array}{l}\text { Hepatocellular } \\
\text { carcinoma }\end{array}$ & Downregulated & Sponge for miR-129-5p & Impedes progression & $(40)$ \\
\hline hsa_circRNA_100338 & $\begin{array}{l}\text { Hepatocellular } \\
\text { carcinoma }\end{array}$ & Upregulated & Sponge for miR-141-3p & $\begin{array}{l}\text { Promotes the metastasis of } \\
\text { hepatocellular carcinoma } \\
\text { cells }\end{array}$ & $(42)$ \\
\hline ciRS-7 & $\begin{array}{l}\text { Hepatocellular } \\
\text { carcinoma }\end{array}$ & Upregulated & Sponge for miR-7 & $\begin{array}{l}\text { Promotes proliferation and } \\
\text { invasion }\end{array}$ & $(41)$ \\
\hline circMTO1 & $\begin{array}{l}\text { Hepatocellular } \\
\text { carcinoma }\end{array}$ & Downregulated & Sponge for miR-9 & $\begin{array}{l}\text { Suppresses proliferation } \\
\text { and invasion }\end{array}$ & $(12)$ \\
\hline hsa_circ_000839 & $\begin{array}{l}\text { Hepatocellular } \\
\text { carcinoma }\end{array}$ & Downregulated & $\begin{array}{l}\text { Probably sponge } \\
\text { for miR- } 200 \mathrm{~b}\end{array}$ & $\begin{array}{l}\text { Suppresses proliferation } \\
\text { and invasion }\end{array}$ & $(43)$ \\
\hline circITCH & Colorectal cancer & Upregulated & $\begin{array}{l}\text { Sponge for miR-7, } \\
\text { miR-17 and miR-214 }\end{array}$ & $\begin{array}{l}\text { Promotes cancer } \\
\text { progression }\end{array}$ & (44) \\
\hline ciRS-7 & Colorectal cancer & Upregulated & Sponge for miR-7 & $\begin{array}{l}\text { Promotes proliferation } \\
\text { and invasion }\end{array}$ & (19) \\
\hline hsa_circ_0020397 & Colorectal cancer & Upregulated & Sponge for miR-138 & Promotes cancer progression & $(45)$ \\
\hline hsa_circ_001569 & Colorectal cancer & Upregulated & Sponge for miR-145 & $\begin{array}{l}\text { Promotes proliferation and } \\
\text { invasion }\end{array}$ & (46) \\
\hline circCCDC66 & Colorectal cancer & Upregulated & $\begin{array}{l}\text { Sponge for miR-33b, } \\
\text { miR-93 and miR-185 }\end{array}$ & $\begin{array}{l}\text { Promotes proliferation, } \\
\text { migration and invasion }\end{array}$ & (47) \\
\hline hsa_circ_0013958 & $\begin{array}{l}\text { Lung } \\
\text { adenocarcinoma }\end{array}$ & Upregulated & Sponge for miR-134 & $\begin{array}{l}\text { Promotes proliferation and } \\
\text { invasion, and inhibits } \\
\text { apoptosis }\end{array}$ & $(48)$ \\
\hline circITCH & Lung cancer & Upregulated & $\begin{array}{l}\text { Sponge for miR-7, } \\
\text { miR-17 and miR-214 }\end{array}$ & Promotes cancer progression & (49) \\
\hline hsa_circ_100290 & Oral cancer & Upregulated & Sponge for miR-29 & Promotes cell growth & $(50)$ \\
\hline circTTBK2 & Glioma & Upregulated & Sponge for miR-217 & $\begin{array}{l}\text { Promotes proliferation, } \\
\text { migration and invasion; } \\
\text { inhibits apoptosis }\end{array}$ & $(51)$ \\
\hline hsa_circRNA_100395 & $\begin{array}{l}\text { Papillary thyroid } \\
\text { carcinoma }\end{array}$ & Upregulated & $\begin{array}{l}\text { Sponge for } \\
\mathrm{miR}-141-3 \mathrm{p} / \mathrm{miR}-200 \mathrm{a}-3 \mathrm{p}\end{array}$ & Promotes cancer progression & $(52)$ \\
\hline
\end{tabular}


Table I. Continued.

\begin{tabular}{|c|c|c|c|c|c|}
\hline Circular RNA & Cancer type & Dysregulation & Action & Role & (Refs.) \\
\hline circHIAT1 & Renal cancer & Upregulated & $\begin{array}{l}\text { Sponge for } \\
\text { miR-195-5p/29a-3p/29c-3p }\end{array}$ & $\begin{array}{l}\text { Enhances migration and } \\
\text { invasion }\end{array}$ & (53) \\
\hline circITCH & $\begin{array}{l}\text { Esophageal squamous } \\
\text { cell carcinoma }\end{array}$ & Upregulated & $\begin{array}{l}\text { Sponge for miR-7, } \\
\text { miR-17 and miR-214 }\end{array}$ & Promotes cancer progression & (54) \\
\hline circFBXW7 & Glioma & Downregulated & Protein coding & $\begin{array}{l}\text { Impedes proliferation and } \\
\text { induces cell cycle arrest }\end{array}$ & (57) \\
\hline circFoxo3 & $\begin{array}{l}\text { Cancer, especially } \\
\text { breast cancer }\end{array}$ & Downregulated & $\begin{array}{l}\text { Interaction with p53, } \\
\text { MDM2 and Foxo } 3\end{array}$ & $\begin{array}{l}\text { Triggers apoptosis and } \\
\text { promotes tumorigenesis }\end{array}$ & (59) \\
\hline circZKSCAN1 & $\begin{array}{l}\text { Hepatocellular } \\
\text { carcinoma }\end{array}$ & Downregulated & $\begin{array}{l}\text { Cooperation with } \\
\text { ZKSCAN1 mRNA }\end{array}$ & Represses cancer progression & (60) \\
\hline hsa_circ_0067934 & $\begin{array}{l}\text { Esophageal squamous } \\
\text { cell carcinoma }\end{array}$ & Upregulated & Unknown & Promotes cell growth & (61) \\
\hline circZNF292 & Glioma & Upregulated & Unknown & $\begin{array}{l}\text { Promotes proliferation, } \\
\text { migration and invasion; } \\
\text { inhibits apoptosis }\end{array}$ & (62) \\
\hline circAmotl1 & Cancer & Upregulated & $\begin{array}{l}\text { Induction of c-Myc } \\
\text { nuclear translocation }\end{array}$ & Promotes tumorigenesis & (63) \\
\hline circBANP & Colorectal cancer & Upregulated & Unknown & $\begin{array}{l}\text { Promotes gastric cancer cell } \\
\text { growth and migration }\end{array}$ & (65) \\
\hline
\end{tabular}

Foxo3, forkhead box O3; ZKSCAN1, zinc finger with KRAB and SCAN domains 1; miR, microRNA; hsa, Homo sapiens.

In breast cancer, Gao et al (33) have detected 3,093 circular RNAs, 18 of which are differentially expressed in adriamycin (ADM)-resistant and native MCF-7 cells. By performing quantitative real-time polymerase chain reaction (qPCR) analysis, they identified that Homo sapiens (hsa)_circ_0006528 is significantly upregulated in ADM-resistant cancer cells. When the expression of hsa_circ_0006528 was interfered with by small inhibitory RNA, the sensitivity of breast cancer cells to ADM decreased significantly. At the same time, downregulation of hsa_circ_0006528 was associated with an increased expression of miRNA-7-5p. This suggests a regulatory role for the hsa_circ_0006528/miR-7-5p/RAF1 axis in ADM-resistant breast cancer (33). In addition, circABCB10 was reported to promote breast cancer proliferation and suppress apoptosis via acting as a sponge for miRNA-1271 (34).

The first circular RNA defined in bladder cancer was circTCF25. By performing microarrays with bladder carcinoma, 469 circular transcripts were identified to be dysregulated compared with the levels in adjacent normal tissue. Multiple bioinformatic approaches were used to select circular RNAs that are involved in cancer-associated pathways via interactions with miRNA. Among those dysregulated circular RNAs, circTCF25 was indicated to sequester miRNA-103a-3p/miRNA-107. Overexpression of circTCF25 was associated with downregulation of miRNA-103a-3p and miRNA-107, increased expression of cyclin (CCN)-dependent kinase 6 (CDK6) and increased cell proliferation and migration in vitro and in vivo. Zhong et al (35) was the first to explore the interactions between circular RNA and miRNA in bladder cancer. Since then, further circular RNAs have been identified to have a regulatory role in bladder cancer via acting as a sponge for miRNAs. In bladder cancer tissues and cell lines, circHIPK3 is significantly downregulated and negatively correlates with the tumor grade and tumor cell invasion as well as lymph node metastasis. Overexpression of circHIPK3 effectively inhibits invasion, migration and angiogenesis of bladder cancer cells in vitro, and suppresses bladder cancer growth and metastasis in vivo. In addition, it has been identified that circHIPK 3 contains two critical binding sites for miRNA-558, which are able to abundantly sequester miRNA-558 and suppress the expression of the miRNA-558 target heparanase (11). CircMYLK and VEGFA were reported to be significantly upregulated in bladder cancer. Upregulation of circMYLK accelerated cell proliferation, migration and tube formation, and caused a rearrangement of the cytoskeleton of bladder cancer cells, while at the same time promoting the growth, angiogenesis and metastasis of bladder cancer xenografts in vitro and in vivo. By contrast, knockdown of circMYLK decreased cell proliferation and motility, and induced apoptosis. Furthermore, upregulation of circMYLK promoted epithelial-mesenchymal transition. These results suggest that circMYLK has an important role in bladder carcinogenesis. To further elucidate the underlying mechanism, it has been indicated that circMYLK directly binds to miRNA-29a and attenuate the suppression of its target VEGFA, which promotes cancer progression through activation of VEGFA/VEGFR2 and the downstream Ras/extracellular signal-regulated kinase pathway (20).

One of the most significantly overexpressed circular RNAs in osteosarcoma is hsa_circ_001564. It has been reported that knockdown of hsa_circ_001564 expression significantly suppressed the cell proliferation, induced cell-cycle arrest 
in $G_{0} / G_{1}$ phase and promoted apoptosis in osteosarcoma cell lines (36). A bioinformatics analysis indicated that hsa_circ_0001564 shares 7 complementary binding regions with miRNA-29c-3p. Ectopic expression of miRNA-29c-3p expression significantly reversed the oncogenic effect of hsa_circ_001564. This result indicates that hsa_circ_0001564 acts as a miRNA-29c-3p sponge to mediate tumorigenicity in osteosarcoma (36). In addition, hsa_circ_0016347, circUBAP2 and circGLI2 all have oncogenic roles in osteosarcoma. It has been demonstrated that hsa_circ_0016347 promotes proliferation, invasion and metastasis of osteosarcoma cells via sponging miRNA-214 and upregulating the expression of caspase-1 (37). CircUBAP2 promotes the growth and reduces the apoptotic rate of osteosarcoma cells via inhibiting the expression of miRNA-143, thus enhancing the expression and function of anti-apoptotic B-cell lymphoma 2 (Bcl-2), which is a direct target of miR-143 (38). In addition, circGLI2 promotes osteosarcoma cell proliferation, migration and invasion by targeting miRNA-125b-5p (39).

In hepatocellular carcinoma, hsa_circ_0005986 functions as a miRNA sponge to repress tumorigenesis. The expression levels of hsa_circ_0005986 in hepatocellular carcinoma tissues were reported to be significantly lower than those in adjacent non-tumorous tissues. Furthermore, downregulation of hsa_circ_0005986 liberates miRNA-129-5p and decreases the expression levels of the miRNA-129-5p-targeted gene Notch1, thus accelerating cell proliferation by promoting the $G_{0} / G_{1}$ to $\mathrm{S}$ phase transition (40). ciRS-7 expression is also upregulated in hepatocellular carcinoma. It has been reported that circ-7 promotes the proliferation and invasion of hepatocellular carcinoma cells through targeting miRNA-7, which directly increases CCNE1 and PI3K catalytic subunit $\delta$ expression. These data suggested that circ-7 acts as an oncogene partly through targeting miRNA-7 in hepatocellular carcinoma (41). hsa_circRNA_100338 has also been indicated to be upregulated in hepatocellular carcinoma. It acts as an endogenous sponge for miRNA-141-3p to promote the metastasis of hepatocellular carcinoma cells (42). By contrast, circMTO1 acts as a sponge for miRNA-9 to suppress hepatocellular carcinoma proliferation and invasion via promoting p21 expression (12). hsa_circ_000839 is another circular RNA that has been identified to be expressed at high levels in hepatocellular carcinoma, but its function remains elusive. Ras homolog family member A (RhoA) is a direct target of miRNA-200b. Binding with miRNA-200b impacts the invasion and migration of hepatocellular carcinoma cells, which is initiated by RhoA. RhoA is positively correlated with hsa_circ_000839, but inversely correlated with miRNA-200b. However, the correlation between hsa_circ_000839 and miRNA-200b is negative. This suggests that miRNA-200b mediates the association between the RhoA gene and hsa_circ_000839 through endogenous competition (43). Further study is required to validate the role of hsa_circ_000839 in hepatocellular carcinoma and to verify the sponging function of hsa_circ_000839.

In colorectal cancer, circITCH expression is usually low compared with that in the peritumoral tissue. CircITCH has a sponging action on miRNA-7, miRNA-17 and miRNA-214, which in turn increases the level of the target of these miRNAs, ITCH. ITCH is a major protein in the $\mathrm{Wnt} / \beta$-catenin pathway that has a significant role in cancer progression. While phosphorylation of dishevelled segment polarity protein 2 (Dvl2) is required for Wnt signaling stabilization, hyperexpression of ITCH promotes the ubiquitination and degradation of phosphorylated Dvl2, thereby inhibiting the Wnt/ $\beta$-catenin pathway. Hence, these results indicate that circITCH may have an inhibitory effect on colorectal cancer by regulating the Wnt pathway (44). Similarly, Weng et al (19) reported that ciRS-7 may be a potential miRNA-7 sponge in colorectal cancer. It has been indicated that elevated ciRS-7 levels in colorectal cancer may act as a sponge for miRNA-7, thus directly impairing the tumor-suppressive effect of miRNA-7. Sponging of miRNA-7 then leads to the activation of the genes downstream of its target, including as EGFR and RAF1 oncogenes, which finally contribute to a more malignant phenotype (19). Another circular RNA, hsa_circ_0020397, is upregulated in colorectal cancer cells and promotes cancer progression via sponging of certain miRNAs. It has been indicated that hsa_circ_0020397 promotes the cell viability and invasion of colorectal cancer cells and inhibits their apoptosis by enhancing the expression of the miRNA-138 targets telomerase reverse transcriptase and programmed death ligand 1 (45). hsa_circ_001569 was also reported to be upregulated in colorectal cancer, acting as a positive regulator in cell proliferation and invasion of colorectal cancer cells by acting as a sponge for miRNA-145, which in turn upregulates functional targets of miRNA-145, namely E2F5, Bcl2-associated athanogene 4 and formin-like 2 (46). circCCDC66 has also been proven to control multiple pathological processes in colon cancer, including cell proliferation, migration, invasion and anchorage-independent growth. It has been indicated that circCCDC66 acts as a sponge on miRNA-33b, miRNA-93 and miRNA-185 via 93 binding sites. In addition, it protects oncogenes, including DNA methyltransferase $3 \beta$, enhancer of zeste 2 polycomb repressive complex 2 subunit, MYC and Yes-associated protein 1 from miRNA attack (47). Taken together, these results highlight the potential oncogenic role of circular RNA in cancer progression and metastasis.

In addition, in other types of cancer, circular RNA has also been indicated to have a significant role. In lung adenocarcinoma, hsa_circ_0013958 is upregulated and promotes cell proliferation and invasion, while inhibiting cell apoptosis. It has been indicated that hsa_circ_0013958 acts as a sponge on miRNA-134, and thus upregulates CCND1, a target of the oncogenic miRNA-134 that has a pivotal role in the development of lung adenocarcinoma (48). Furthermore, as in colorectal cancer, circITCH has also been proven to have a tumor suppressor role in lung cancer. A previous study indicated that circITCH acts as sponge for oncogenic miRNA-7 and miRNA-214 to enhance the expression of Itchy E3 ubiquitin protein ligase (ITCH) and thus suppress the activation of Wnt/ $\beta$-catenin signalling (49). In oral cancer, hsa_circ_100290 promoted cell growth via sponging of miRNA-29, which liberated CDK6 expression (50). CircTTBK2 is upregulated in glioma tissues and cell lines. Enhanced expression of circTTBK2 promotes cell proliferation, migration and invasion, while inhibiting apoptosis. miRNA-217 is downregulated in glioma tissues and cell lines. It has been reported that circTTBK2 acts as a miRNA-217 sponge, thus downregulating the expression of HNF1 homeobox B, a direct target of miRNA-217. This suggests that circTTBK2 has an oncogenic 
role in glioma cells (51). In human papillary thyroid carcinoma, hsa_circRNA_100395 is one of the downregulated circular RNAs. It has been identified that hsa_circRNA_100395 targets miRNA-141-3p/miRNA-200a-3p, thus leading to dysregulation of 7 cancer-associated genes: E2F3, glutaminase, CCND2, PTEN, CCNG1, cell division cycle (CDC)25B and zinc finger protein, FOG family member 2 . These results indicate that hsa_circRNA_100395 is important in the pathogenesis of human papillary thyroid carcinoma, but further study is required to elucidate its function and mechanism of action on miRNA-141-3p/miRNA-200a-3p (52). In renal cancer, circHIAT1 is downregulated. Wang et al (53) indicated that circHIAT1 participates in androgen receptor (AR)-mediated tumor progression. In clear-cell renal cell carcinoma, AR suppressed circHIAT1 expression via regulating the expression of HIAT1, the host of circHIAT1, at the transcriptional level. CircHIAT1 acts as a sponge for miRNA-195-5p/29a-3p/29c-3p and increases the expression of the miRNA-targeted gene CDC42 to enhance the migration and invasion of clear-cell renal cell carcinoma cells. Targeting AR directly leads to the activation of circHIAT1, which ultimately suppresses cancer progression. Taken together, these results suggest that circHIAT1 serves as an inhibitor of metastasis via suppressing AR-mediated migration and invasion of clear-cell renal cell carcinoma cells. In esophageal squamous cell carcinoma, circITCH has been proven to suppress cancer progression via the same mechanisms as in colorectal and lung cancer. CircITCH acts as a sponge for oncogenic miRNA-7 and miRNA-214 to enhance ITCH expression and thus suppress the activation of $\mathrm{Wnt} / \beta$-catenin signalling (54).

Circular RNAs that may be translated into proteins to regulate cancer cells. Most circular RNAs arise from the protein-coding regions of genes. Although circular RNAs have been categorized as a non-coding RNAs, recent studies have indicated that certain circular RNAs may be translated into proteins in eukaryotic cells. Wang et al (55) first reported on the presence of consensus N6-methyladenosine (m6A) motifs that are enriched in circular RNA. In addition, only a single m6A site is sufficient to initiate translation in human cells. Two years later, a study by the same group demonstrated that the m6A-driven translation of circular RNAs is extensive and that circular RNA translation requires the participation of the m6A reader YTH N6-methyladenosine RNA binding protein 3 and the translation initiation factors eukaryotic translation initiation factor (eIF) $4 \gamma 2$ and eIF 3 subunit A (56). This discovery extends the current awareness of the functions of circular RNAs and suggests their potential role in regulating gene expression. In human cancer, circFBXW7 was the first circular RNA to be defined as encoding for protein. It has been reported that circFBXW7 is abundantly expressed in the normal human brain and encodes for a 21-kDa protein termed F-box and WD repeat domain containing 7 (FBXW7)-185aa. It has been indicated that the levels of circ-FBXW7 and FBXW7-185aa were significantly reduced in glioblastoma compared with the levels in paired tumor-adjacent samples. Upregulation of FBXW7-185aa impedes cell proliferation and induces cell cycle arrest, while FBXW7-185aa knockdown contributes to more malignant phenotypes in vivo and in vitro. Furthermore, FBXW7-185aa is able to reduce the half-life of c-Myc via antagonizing ubiquitin-specific peptidase 28-induced c-Myc stabilization (57). This research further validates the phenomenon that endogenous circular RNA may be translated into protein in human cells.

Circular RNAs that regulate cancer via protein-binding patterns. Despite the above studies demonstrating that circular RNAs act as microRNA sponges and are able to encode for proteins, other biological functions of circular RNAs in cancer remain largely elusive. Previously, circFoxo3 was reported to cause cell cycle arrest by binding with cell cycle protein CDK2 and $\mathrm{CDK}$ inhibitor 1 or $\mathrm{p} 21$, resulting in the formation of a ternary complex. In general, CDK2 facilitates cell cycle entry via interacting with CCNA and CCNE, while p21 inhibits these interactions and induces cell cycle arrest. Hence, the ternary complex formed by the circFoxo3-p21-CDK2 interaction interrupts the function of CDK2 and then blocks cell cycle progression. This result, for the first time, put forward the protein-binding potential of circular RNA (58). Later, a similar protein-binding pattern was also identified in human cancer. Du et al (59) demonstrated this in a panel of human cancer samples and cancer cells. They reported that circFoxo3 was minimally expressed in human cancer, particularly breast cancer. During cancer cell apoptosis, circFoxo3 expression was significantly elevated. Silencing of endogenous circ-Foxo3 expression enhanced cancer cell viability, whereas induction of ectopic circ-Foxo3 triggered stress-induced apoptosis and inhibited tumor xenograft growth. Furthermore, it has been indicated that circFoxo3 increased the level of forkhead box (Fox)o3 protein but repressed that of p53. MDM2 has a significant role in repressing apoptosis via repression of the expression of Foxo3, p53 and the Foxo3 downstream molecule p53 upregulated modulator of apoptosis (Puma). In addition, circFoxo3 has been identified to exert its function through binding with MDM2, p53 or their complex. By binding to MDM2 and p53 together, circFoxo3 promotes the ubiquitination of p53 induced by MDM2 and subsequently leads to p53 degradation. In addition, due to the lower binding affinity between Foxo3 and circFoxo3, circFoxo3 prevents Foxo3 ubiquitination and degradation induced by MDM2 binding, resulting in increased levels of Foxo3 protein and expression of its downstream molecule Puma. This in turn promotes cell apoptosis (59).

Roles of other circular RNAs in cancer. hsa_circ_0067934 is upregulated in esophageal squamous cell carcinoma. In vitro silencing of hsa_circ_0067934 inhibits the proliferation and migration of esophageal squamous cell carcinoma cells and blocks cell cycle progression (60). CircZNF292 has a critical role in the progression of human glioma. It has been identified that silencing of circZNF292 significantly suppresses tube formation by inhibiting cell proliferation and inducing cell cycle arrest (61). Yang et al (62) reported that circAmotl1 promotes tumorigenesis by inducing the nuclear translocation of c-Myc. CircAmotl1 is highly expressed in cancer. Ectopic expression of circAmotl1 increases the retention of nuclear c-Myc, which is then able to enhance the stability of c-Myc and upregulate the targets of c-Myc by increasing the affinity between c-Myc and the promoter of its targets. CircBANP is overexpressed in colorectal cancer tissues. Knockdown 
of circBANP significantly attenuates colorectal cancer cell proliferation (63). Furthermore, hsa_circ_0000096 is significantly downregulated in gastric cancer tissues and cell lines, and is able to promote gastric cancer cell growth and migration by regulating CCND1, CDK6, matrix metalloproteinase (MMP)-2 and MMP-9 (64). In hepatocellular carcinoma, circZKSCAN1 expression is significantly lower compared with that in matched adjacent normal tissues. It has been indicated that decreased levels of CircZKSCAN1 are only associated with tumor size. Silencing of zinc finger with KRAB and SCAN domains 1 (ZKSCAN1) mRNA and circZKSCAN1 together promotes the proliferation, migration and invasion of hepatocellular carcinoma cells, while overexpression of ZKSCAN1 mRNA and circZKSCAN1 represses the progression of hepatocellular carcinoma cells in vivo and in vitro. However, these effects were not present if only one of the two molecules was silenced. In addition, circZKSCAN1 is thought to mediate several cancer-associated signaling pathways, while ZKSCAN1 mRNA mainly regulates cellular metabolism. Hence, these results revealed that the two post-translational products (ZKSCAN1 mRNA and circZKSCAN1) may cooperate closely to regulate the growth, migration and invasion of hepatocellular carcinoma cells (65). It is therefore suggested that circular RNAs hold the potential to be applied as novel therapeutic targets in cancer.

\section{Circular RNAs as potential biomarkers in cancer}

Except for the above biological function of circular RNAs in cancer, an increasing number of circular RNAs have been identified as potential biomarkers in cancer. Certain biomarkers are present in plasma, while others are detected in tissues. To further clarify the role of circular RNAs in cancer, studies indicating that circular RNAs may be able to serve as biomarkers in cancer are further discussed below (Table II).

Plasma-based diagnostic biomarkers. Based on data from plasma samples from gastric cancer patients,hsa_circ_0000745 is downregulated in patients with gastric cancer compared with that in healthy control individuals. It has been reported that the plasma levels of hsa_circ_0000745 are correlated with the tumor-node-metastasis stage with an area under the receiver operating characteristic curve (AUC) of 0.683. At the same time, combination of the plasma hsa_circ_0000745 levels with the carcinoembryonic antigen (CEA) levels increased the AUC to 0.775 . These results suggest that hsa_circ_0000745 may be used as a potential diagnostic biomarker for gastric cancer (66). In addition, hsa_circ_0001649 is significantly downregulated in gastric cancer tissues compared with that in paired adjacent normal tissues. However, in serum, hsa_circ_0001649 is significantly upregulated after surgery. The AUC in the study was 0.834 , which suggests that hsa_circ_0001649 holds potential value as a diagnostic biomarker (67). hsa_circ_0000190 is also downregulated in gastric cancer tissues and plasma samples. The expression levels of hsa_circ_0000190 are significantly correlated with the tumor diameter, lymphatic metastasis, distal metastasis, tumor-nodes-metastasis (TNM) stage and carbohydrate antigen (CA)19-9 levels in gastric cancer. The AUC for hsa_circ_0000190 in tissues and plasma reached 0.75 and 0.60 , respectively. When combining tissue and plasma levels, the sensitivity and specificity reached 0.712 and 0.750 , respectively, and at the same time, the AUC increased to 0.775 (68). Furthermore, hsa_circ_0014717 was reported to be significantly downregulated in $77.2 \%$ of gastric cancer tissues. Its levels in gastric cancer tissues are associated with the tumor stage, distal metastasis, and the tissue levels of CEA and CA19-9. More importantly, hsa_circ_0014717 may stably exist in human gastric juice, which suggests that it may serve as a potential human fluid biomarker. Hence, further study is urgently required to elucidate the role of hsa_circ_0014717 in gastric juice in predicting the clinical features of gastric cancer (16).

Tissue-based diagnostic biomarkers. The hsa_circ_0004018 levels in hepatocellular carcinoma tissue are significantly lower than those in para-tumorous tissue. It has been suggested that hsa_circ_0004018 levels are correlated with the serum $\alpha$-fetoprotein (AFP) levels, tumor diameter, differentiation, the Barcelona Clinic Liver Cancer (BCLC) stage and the TNM stage. At the same time, comparison of the levels of hsa_circ_0004018 among hepatocellular carcinoma and para-tumorous tissues, as well as liver tissues from patients with chronic hepatitis, indicates a diagnostic value for hsa_circ_0004018 with an AUC of 0.848 and a sensitivity and specificity of 0.716 and 0.815 , respectively (69). Similarly, hsa circ_0005986 is downregulated in hepatocellular carcinoma. Its low expression has been proven to be correlated with a family history of chronic hepatitis B, tumor diameter, microvascular invasion and BCLC stage (40). By contrast, hsa_circ_0005075 has been reported to be significantly upregulated in hepatocellular carcinoma. Elevated hsa_circ_0005075 expression correlates with the tumor size of hepatocellular carcinoma and has a good diagnostic potential, with an AUC of 0.94 (70). CiRS-7 is significantly elevated in hepatocellular carcinoma. In patients with 'an age of $<40$ years, serum AFP $\geq 400 \mathrm{ng} / \mu \mathrm{l}$ and hepatic microvascular invasion', a high correlation with the expression of ciRS-7 was identified with a cut-off value of $0.135 \mathrm{ng} / \mathrm{ml}$ (71). In addition, hsa_circ_0001649 expression is also significantly downregulated in hepatocellular carcinoma with an AUC of 0.63. Its expression is correlated with tumor size and the occurrence of tumor embolus (72).

In colorectal cancer, Zhang et al (73) reported that hsa_circRNA_103809 and hsa_circRNA_104700 levels were significantly decreased compared with those in normal tissues. Lower expression of hsa_circRNA_103809 was identified as a significant predictive factor of lymph node metastasis, TNM stage and distal metastasis. The AUCs for hsa_circRNA_103809 and hsa_circRNA_104700 were 0.699 and 0.616, respectively. Although their AUCs appear not to be very good currently, the above data does indicate that hsa_circRNA_104700 and hsa_circRNA_103809 could serve as biomarkers for the diagnosis of colorectal cancer (73). Therefore, enlarging the testing samples is required to furtherly evaluate the potential role of hsa_circRNA_104700 and hsa_circRNA in cancer diagnosis.

In acute myeloid leukemia (AML), hsa_circ_0004277 is downregulated, and its levels may be used to distinguish individuals with AML from healthy individuals with an AUC of 0.957. In addition, hsa_circ_0004277 displays dynamic expressional changes according to the progressive stage of 
Table II. Circular RNAs with potential as biomarkers in cancer.

\begin{tabular}{|c|c|c|c|c|c|c|}
\hline Circular RNA & Cancer type & Dysregulation & Utility & Correlated or predicted parameter & Sample & (Refs.) \\
\hline hsa_circ_0000745 & Gastric cancer & Downregulated & Diagnosis & Node metastasis & Plasma & $(66)$ \\
\hline hsa_circ_0001649 & Gastric cancer & Downregulated & Diagnosis & & Plasma & $(67)$ \\
\hline hsa_circ_0000190 & Gastric cancer & Downregulated & Diagnosis & $\begin{array}{l}\text { Tumor diameter, lymphatic } \\
\text { metastasis, distal metastasis, } \\
\text { TNM stage and CA19-9 levels }\end{array}$ & Plasma & $(68)$ \\
\hline hsa_circ_0014717 & Gastric cancer & Downregulated & Diagnosis & $\begin{array}{l}\text { Tumor stage, distal metastasis, } \\
\text { tissue carcinoembryonic antigen } \\
\text { and CA19-9 expression }\end{array}$ & $\begin{array}{l}\text { Gastric } \\
\text { juice }\end{array}$ & (16) \\
\hline hsa_circ_0004018 & $\begin{array}{l}\text { Hepatocellular } \\
\text { carcinoma }\end{array}$ & Downregulated & Diagnosis & $\begin{array}{l}\text { Serum AFP level, tumor diameter, } \\
\text { differentiation, BCLC stage and } \\
\text { TNM stage }\end{array}$ & Tissue & (69) \\
\hline hsa_circ_0005986 & $\begin{array}{l}\text { Hepatocellular } \\
\text { carcinoma }\end{array}$ & Upregulated & Diagnosis & $\begin{array}{l}\text { Chronic hepatitis B family history, } \\
\text { tumor diameter, microvascular } \\
\text { invasion and BCLC stage }\end{array}$ & Tissue & $(40)$ \\
\hline hsa_circ_0005075 & $\begin{array}{l}\text { Hepatocellular } \\
\text { carcinoma }\end{array}$ & Downregulated & Diagnosis & Tumor size & Tissue & (70) \\
\hline ciRS-7 & $\begin{array}{l}\text { Hepatocellular } \\
\text { carcinoma }\end{array}$ & Upregulated & Diagnosis & $\begin{array}{l}\text { Age }<40 \text { years, serum AFP } \\
\geq 400 \mathrm{ng} / \mu 1 \text { and hepatic } \\
\text { microvascular invasion }\end{array}$ & Tissue & $(71)$ \\
\hline hsa_circ_0001649 & $\begin{array}{l}\text { Hepatocellular } \\
\text { carcinoma }\end{array}$ & Downregulated & Diagnosis & $\begin{array}{l}\text { Tumor size and occurrence of } \\
\text { tumor embolus }\end{array}$ & Tissue & (72) \\
\hline hsa_circRNA_103809 & Colorectal cancer & Downregulated & Diagnosis & $\begin{array}{l}\text { Lymph node metastasis, } \\
\text { TNM stage and distal metastasis }\end{array}$ & Tissue & (73) \\
\hline hsa_circRNA_104700 & Colorectal cancer & Downregulated & Diagnosis & $\begin{array}{l}\text { Lymph node metastasis, TNM } \\
\text { stage and distal metastasis }\end{array}$ & Tissue & (73) \\
\hline hsa_circ_0004277 & $\begin{array}{l}\text { Acute myeloid } \\
\text { leukemia }\end{array}$ & Downregulated & Diagnosis & $\begin{array}{l}\text { Distinguishing individuals with } \\
\text { cancer from healthy individuals }\end{array}$ & Tissue & (74) \\
\hline hsa_circ_0013958 & $\begin{array}{l}\text { Lung } \\
\text { adenocarcinoma }\end{array}$ & Upregulated & Diagnosis & $\begin{array}{l}\text { Distinguishing TNM III-IV } \\
\text { vs. TNM I-II }\end{array}$ & Tissue & $(48)$ \\
\hline hsa_circ_0067934 & $\begin{array}{l}\text { Esophageal } \\
\text { squamous cell } \\
\text { carcinoma }\end{array}$ & Upregulated & Diagnosis & Poor differentiation & Tissue & $(61)$ \\
\hline $\begin{array}{l}\text { hsa_circ_006054, } \\
\text { hsa_circ_100219 and } \\
\text { hsa_circ_406697 }\end{array}$ & Breast cancer & Upregulated & Diagnosis & $\begin{array}{l}\text { Combined together to } \\
\text { distinguish individuals with cancer } \\
\text { from healthy individuals }\end{array}$ & Tissue & $(75)$ \\
\hline circMTO1 & $\begin{array}{l}\text { Hepatocellular } \\
\text { carcinoma }\end{array}$ & Downregulated & Prognosis & Poor overall survival & Tissue & (12) \\
\hline circFBXW7 & Glioblastoma & Downregulated & Prognosis & Increased overall survival & Tissue & (57) \\
\hline circRNA_100338 & $\begin{array}{l}\text { Hepatocellular } \\
\text { carcinoma }\end{array}$ & Downregulated & Prognosis & $\begin{array}{l}\text { Increased overall survival, } \\
\text { determination of metastasis and } \\
\text { tumor grades }\end{array}$ & Tissue & $(42)$ \\
\hline hsa_circ_0006633 & Gastric cancer & Upregulated & Diagnosis & $\begin{array}{l}\text { Distal metastasis and tissue } \\
\text { carcinoembryonic antigen level }\end{array}$ & Tissue & (76) \\
\hline hsa_circ_0058246 & Cancer & Upregulated & Diagnosis & $\begin{array}{l}\text { Lymph node metastasis and } \\
\text { recurrence }\end{array}$ & Tissue & (77) \\
\hline circPVT1 & Gastric cancer & Upregulated & Prognosis & $\begin{array}{l}\text { Late T-stage (T4) tumors and } \\
\text { positive neural invasion, shorter } \\
\text { overall survival }\end{array}$ & Tissue & $(31)$ \\
\hline ciRS-7 & Colorectal cancer & Upregulated & Prognosis & Poorer overall survival & Tissue & (19) \\
\hline
\end{tabular}


AML. Compared with the levels in healthy controls, lower levels of hsa_circ_0004277 have been identified in newly diagnosed AML patients without prior treatment. No significant differences in hsa_circ_0004277 levels were detected between those patients who achieved complete remission and the healthy controls, which indicates that the treatment restores hsa_circ_0004277 expression. However, in relapsed or refractory patients, downregulated hsa_circ_0004277 expression is observed again. Hence, these results suggest that hsa_circ_0004277 has a promising potential to assist with the diagnosis and follow-up of AML patients (74).

Circular RNA also has a promising role as a diagnostic biomarker in other types of cancer. In lung adenocarcinoma, it has been indicated that the expression of hsa_circ_0013958 is highly associated with TNM stage III/IV compared with TNM stage I/II, with an AUC of 0.874 and with a sensitivity and specificity of 0.762 and 0.857 , respectively. In addition, in plasma, the AUC is 0.794 , and the sensitivity and specificity are 0.667 and 0.933 , respectively. These results indicate a promising potential for hsa_circ_0013958 in the diagnosis of lung adenocarcinoma (48). In esophageal squamous cell carcinoma, hsa_circ_0067934 is significantly overexpressed compared with its levels in paired adjacent normal tissues. It has been reported that higher levels of hsa_circ_0067934 are significantly associated with poor differentiation of esophageal squamous cell carcinoma patients, which suggests that hsa_circ_0067934 represents a novel potential diagnostic biomarker for esophageal squamous cell carcinoma (60). In breast cancer, hsa_circ_006054, hsa_circ_100219 and hsa_ circ_406697 are downregulated compared with those in the adjacent non-tumorous tissue. The combined expression levels of hsa_circ_006054,hsa_circ_100219 and hsa_circ_406697 have a distinguished potential for breast cancer diagnosis, with an AUC of 0.82 (75).

Tissue-based prognostic biomarkers. The expression of circMTO1 is significantly decreased in hepatocellular carcinoma tissues when compared with that in matched non-tumorous tissues. A Kaplan-Meier survival curve analysis suggested that a decreased circMTO1 expression is correlated with a shortened survival of patients. In addition, $76.89 \mathrm{ng} / \mathrm{ml}$ the cut-off value of circMTO1 may be used as an efficient prognostic indicator of poor survival in hepatocellular carcinoma patients (12). The ability of circFBXW7 to encode for protein was mentioned above. Compared with the levels in adjacent normal brain tissues, circ-FBXW7 expression is significantly lower in glioblastoma tissues. However, in glioblastoma patients, it has been indicated that elevated levels of circFBXW7 are associated with an increased total survival time compared with lower circ-FBXW7 expression. The median survival time in the higher circFBXW7 expression group was 24.2 months, compared with 11.7 months in the group with lower circFBXW7 expression (57). This suggests a novel potential role for circFBXW7 in the prognosis of glioblastoma. CircRNA_100338 is upregulated in hepatocellular carcinoma. As mentioned above, circRNA_100338 promotes cancer metastasis via sequestering miRNA-141. A clinical study has identified that hepatocellular carcinoma patients with lower circRNA_100338 levels had survival rates of $72.0 \%$ compared with $42.9 \%$ in patients with higher circRNA_100338 levels. Furthermore, they also indicated that the expression of circRNA_100338 was not associated with age or sex but was significantly correlated with numerous clinicopathological parameters of metastasis, including the TNM stage, vascular invasion and lung metastasis. These results indicate that circRNA_100338 affects the survival rate of hepatocellular carcinoma patients by regulating cancer metastasis (42).

sa_circ_0006633 is downregulated in $79.2 \%$ of gastric cancer tissues compared with those in adjacent non-tumorous tissues. Downregulation of hsa_circ_0006633 is positively associated with distal metastasis and tissue CEA levels (76). hsa_circ_0058246 is elevated in tumor specimens from patients, particularly those with lymph node metastasis and recurrence (77). As mentioned above, circPVT1 acts as a sponge for miRNA-125 to promote cell proliferation in gastric cancer. Chen et al (31) indicated that lower levels of circPVT1 are a significant predictive factor for late T-stage (T4) tumors and neural invasion. In addition, compared with the patients with higher levels of circPVT1, patients with lower levels of circPVT1 exhibited significantly shorter overall survival, with a median survival of 20 vs. 46 months, and shorter progression-free survival, with a median survival of 17 vs. 36 months. In colorectal cancer, ciRS-7 has emerged as an independent risk factor for overall survival. Overexpression of ciRS-7 was associated with poorer patient survival $(\mathrm{P}=0.0224$ and 0.0061 in the training and validation cohorts, respectively), which suggest that higher ciRS-7 levels in colorectal cancer predict poorer overall survival (19).

In a word, circular RNAs serve as novel biomarkers that may be used in cancer screening based on non-invasive biomarker detection. Unlike other biomarkers, circular RNAs have advantages including greater specificity and sensitivity and higher abundance, while they are just as accessible for detection. Of note, some studies have reported that the AUC and the specificity/sensitivity for circular RNA as a biomarker in cancer were quite poor, however, with regard to its highly stability, circular RNAs could be used in addition to or in combination with other markers to enhance the accuracy and/or capacity of diagnosis and prognosis.

\section{Perspectives}

Although circular RNA has been known for 3 decades, it was not until the last 3 years that researchers have begun to focus on this type of RNA. Circular RNAs are abundant and conserved endogenous RNAs. Despite being transcribed from the same gene locus, circular RNA is expressed more abundantly in cells than the linear form. Circular RNAs have been proven to exhibit tissue or cell type specificity and may regulate cell behavior through multiple pathways. In cancer, numerous studies have indicated that circular RNA may serve as a potential biomarker and therapeutic target.

It has been demonstrated that differential expression of certain circular RNA has the capacity to predict the clinical outcomes of cancer patients. For instance, ciRS-7 and circHIPK3 are able to predict the tumor grade, metastasis and drug resistance of cancer patients, while other circular RNAs, including circFBXW7, circMTO1 and ciRS-7 are prognostic indicators with the ability to predict parameters including overall survival and recurrence. In spite of the numerous advantages of circular 
RNAs as biomarkers in cancer, several drawbacks, which make the application of circular RNA difficult at present, still require addressing. First, studies regarding circular RNA as biomarkers in cancer have mostly assessed one single circular RNA with hundreds rather than thousands of samples. Thus, it is more difficult to estimate the potential of certain circular RNAs to serve as biomarkers in cancer. To improve this, studies on the ability of multiple circular RNAs to comprehensively analyze the general situation in human patients are required. In future studies, an increased sample size is also desirable. Furthermore, most studies performed qPCR to compare the expression of circular RNAs between cancerous and normal tissue. Tissue is a complex and consists of multiple cell types; hence, qPCR on tissue samples may not accurately reflect the expression of circular RNA in cancer cells or normal cells, as cancer cells with decreased expression of circular RNA may be diluted by adjacent cells with an increased expression to thereby falsify the results. In situ hybridization is a procedure that intuitively reflects the real level of circular RNA expression in cancer cells within a tissue. Hence, in situ hybridization experiments are urgently required to further verify the differential expression of further circular RNAs in cancer.

Furthermore, circular RNA has 4 major functions in cancer: Protein binding, microRNA sponging, and regulation of transcription and protein translation. It has been suggested that circular RNA regulates carcinogenesis and cancer progression via these 3 processes. Aberrant expression of circular RNA directly interferes with the biological features of cancer cells, including their proliferation, cell cycle, apoptosis and metastasis. Hence, these results indicate that circular RNA may serve as a potential therapeutic target in cancer. However, as only few circular RNAs have been identified, targeting the known circular RNAs is not sufficient to control the entire intracellular change. In addition, interference with one circular RNA may potentially cause cellular changes beyond the intended one. Therefore, prior to using circular RNA as a therapeutic target in cancer, further studies are required elucidate their role in cancer and to identify additional circular RNAs with a role in cancer.

\section{Acknowledgements}

Not applicable.

\section{Funding}

This study was funded by the National Natural Science Foundation of China (grant nos. U1301221, 81572514, 814723 84, 81402106, 81372729 and 81272808).

\section{Availability of data and materials}

The analyzed data sets generated during the study are available from the corresponding author on reasonable request.

\section{Authors' contributions}

TL conceptualized this review, GZ and MH prepared the tables, NJ professionally edited the manuscript and YS wrote the manuscript.

\section{Ethics approval and consent to participate}

Not applicable.

\section{Patient consent for publication}

Not applicable.

\section{Competing of interests}

The authors declare that they have no competing interests.

\section{References}

1. Beermann J, Piccoli MT, Viereck J and Thum T: Non-coding RNAs in development and disease: Background, mechanisms, and therapeutic approaches. Physiol Rev 96: 1297-1325, 2016.

2. He J, Xie Q, Xu H, Li J and Li Y: Circular RNAs and cancer. Cancer Lett 396: 138-144, 2017.

3. Koch L: RNA: Translated circular RNAs. Nat Rev Genet 18: 272-273, 2017.

4. Jeck WR and Sharpless NE: Detecting and characterizing circular RNAs. Nat Biotechnol 32: 453-461, 2014.

5. Hsu MT and Coca-Prados M: Electron microscopic evidence for the circular form of RNA in the cytoplasm of eukaryotic cells. Nature 280: 339-340, 1979.

6. Nigro JM, Cho KR, Fearon ER, Kern SE, Ruppert JM, Oliner JD, Kinzler KW and Vogelstein B: Scrambled exons. Cell 64: 607-613, 1991.

7. Capel B, Swain A, Nicolis S, Hacker A, Walter M, Koopman P, Goodfellow P and Lovell-Badge R: Circular transcripts of the testis-determining gene Sry in adult mouse testis. Cell 73: 1019-1030, 1993.

8. Salzman J, Gawad C, Wang PL, Lacayo N and Brown PO: Circular RNAs are the predominant transcript isoform from hundreds of human genes in diverse cell types. PLoS One 7: e30733, 2012.

9. Salzman J, Chen RE, Olsen MN, Wang PL and Brown PO: Cell-type specific features of circular RNA expression. PLoS Genet 9: e1003777, 2013.

10. Jeck WR, Sorrentino JA, Wang K, Slevin MK, Burd CE, Liu J, Marzluff WF and Sharpless NE: Circular RNAs are abundant, conserved, and associated with ALU repeats. RNA 19: 141-157, 2013.

11. Li Y, Zheng F, Xiao X, Xie F, Tao D, Huang C, Liu D, Wang M, Wang L, Zeng F and Jiang G: CircHIPK3 sponges miR-558 to suppress heparanase expression in bladder cancer cells. EMBO Rep 18: 1646-1659, 2017.

12. Han D, Li J, Wang H, Su X, Hou J, Gu Y, Qian C, Lin Y, Liu X, Huang M, et al: Circular RNA circMTO1 acts as the sponge of microRNA-9 to suppress hepatocellular carcinoma progression. Hepatology 66: 1151-1164, 2017.

13. Dou Y, Cha DJ, Franklin JL, Higginbotham JN, Jeppesen DK, Weaver AM, Prasad N, Levy S, Coffey RJ, Patton JG and Zhang B: Circular RNAs are down-regulated in KRAS mutant colon cancer cells and can be transferred to exosomes. Sci Rep 6: 37982, 2016.

14. Li Y, Zheng Q, Bao C, Li S, Guo W, Zhao J, Chen D, Gu J, He X and Huang S: Circular RNA is enriched and stable in exosomes: A promising biomarker for cancer diagnosis. Cell Res 25: 981-984, 2015.

15. Li P, Chen S, Chen H, Mo X, Li T, Shao Y, Xiao B and Guo J: Using circular RNA as a novel type of biomarker in the screening of gastric cancer. Clin Chim Acta 444: 132-136, 2015.

16. Shao Y, Li J, Lu R, Li T, Yang Y, Xiao B and Guo J: Global circular RNA expression profile of human gastric cancer and its clinical significance. Cancer Med 6: 1173-1180, 2017.

17. Han YN, Xia SQ, Zhang YY, Zheng JH and Li W: Circular RNAs: A novel type of biomarker and genetic tools in cancer. Oncotarget 8: 64551-64563, 2017.

18. Hansen TB, Kjems J and Damgaard CK: Circular RNA and miR-7 in cancer. Cancer Res 73: 5609-5612, 2013.

19. Weng W, Wei Q, Toden S, Yoshida K, Nagasaka T, Fujiwara T, Cai S, Qin H, Ma Y and Goel A: Circular RNA ciRS-7-A promising prognostic biomarker and a potential therapeutic target in colorectal cancer. Clin Cancer Res 23: 3918-3928, 2017. 
20. Zhong Z, Huang M, Lv M, He Y, Duan C, Zhang L and Chen J: Circular RNA MYLK as a competing endogenous RNA promotes bladder cancer progression through modulating VEGFA/VEGFR2 signaling pathway. Cancer Lett 403: 305-317, 2017.

21. Shi Y: Mechanistic insights into precursor messenger RNA splicing by the spliceosome. Nat Rev Mol Cell Biol 18: 655-670, 2017.

22. Chen LL: The biogenesis and emerging roles of circular RNAs. Nat Rev Mol Cell Biol 17: 205-211, 2016.

23. Ashwal-Fluss R, Meyer M, Pamudurti NR, Ivanov A, Bartok O, Hanan M, Evantal N, Memczak S, Rajewsky N and Kadener S: CircRNA biogenesis competes with pre-mRNA splicing. Mol Cell 56: 55-66, 2014.

24. Zhang XO, Wang HB, Zhang Y, Lu X, Chen LL and Yang L: Complementary sequence-mediated exon circularization. Cell 159: 134-147, 2014.

25. Moore MJ and Proudfoot NJ: Pre-mRNA processing reaches back to transcription and ahead to translation. Cell 136: 688-700, 2009.

26. Zhang Y, Zhang XO, Chen T, Xiang JF, Yin QF, Xing YH, Zhu S, Yang L and Chen LL: Circular intronic long noncoding RNAs. Mol Cell 51: 792-806, 2013.

27. Lu Z, Filonov GS, Noto JJ, Schmidt CA, Hatkevich TL, Wen Y, Jaffrey SR and Matera AG: Metazoan tRNA introns generate stable circular RNAs in vivo. RNA 21 $1554-1565,2015$.

28. Hansen TB, Jensen TI, Clausen BH, Bramsen JB, Finsen B, Damgaard CK and Kjems J: Natural RNA circles function as efficient microRNA sponges. Nature 495: 384-388, 2013.

29. Zheng Q, Bao C, Guo W, Li S, Chen J, Chen B, Luo Y, Lyu D, $\mathrm{Li}$ Y, Shi G, et al: Circular RNA profiling reveals an abundant circHIPK3 that regulates cell growth by sponging multiple miRNAs. Nat Commun 7: 11215, 2016.

30. Pan H, Li T, Jiang Y, Pan C, Ding Y, Huang Z, Yu H and Kong D: Overexpression of circular RNA ciRS-7 abrogates the tumor suppressive effect of miR-7 on gastric cancer via PTEN/PI3K/AKT signaling pathway. J Cell Biochem 119: 440-446, 2018

31. Chen J, Li Y, Zheng Q, Bao C, He J, Chen B, Lyu D, Zheng B $\mathrm{Xu} \mathrm{Y}$, Long Z, et al: Circular RNA profile identifies circPVT1 as a proliferative factor and prognostic marker in gastric cancer. Cancer Lett 388: 208-219, 2017.

32. Zhang J, Liu H, Hou L, Wang G, Zhang R, Huang Y, Chen X and Zhu J: Circular RNA LARP4 inhibits cell proliferation and invasion of gastric cancer by sponging miR-424-5p and regulating LATS1 expression. Mol Cancer 16: 151, 2017.

33. Gao D, Zhang X, Liu B, Meng D, Fang K, Guo Z and Li L: Screening circular RNA related to chemotherapeutic resistance in breast cancer. Epigenomics 9: 1175-1188, 2017.

34. Liang HF, Zhang XZ, Liu BG, Jia GT and Li WL: Circular RNA circ-ABCB10 promotes breast cancer proliferation and progression through sponging miR-1271. Am J Cancer Res 7: 1566-1576, 2017.

35. Zhong Z, Lv M and Chen J: Screening differential circular RNA expression profiles reveals the regulatory role of circTCF25-miR-103a-3p/miR-107-CDK6 pathway in bladder carcinoma. Sci Rep 6: 30919, 2016.

36. Song YZ and Li JF: Circular RNA hsa_circ_0001564 regulates osteosarcoma proliferation and apoptosis by acting miRNA sponge. Biochem Biophys Res Commun 495: 2369-2375, 2018

37. Jin $H$, Jin $X$, Zhang $H$ and Wang W: Circular RNA hsa-circ-0016347 promotes proliferation, invasion and metastasis of osteosarcoma cells. Oncotarget 8: 25571-25581, 2017.

38. Zhang H, Wang G, Ding C, Liu P, Wang R, Ding W, Tong D, Wu D, Li C, Wei Q, et al: Increased circular RNA UBAP2 acts as a sponge of miR-143 to promote osteosarcoma progression. Oncotarget 8: 61687-61697, 2017.

39. Li JF and Song YZ: Circular RNA GLI2 promotes osteosarcoma cell proliferation, migration, and invasion by targeting miR-125b-5p. Tumour Biol 39: 1010428317709991, 2017.

40. Fu L, Chen Q, Yao T, Li T, Ying S, Hu Y and Guo J: Hsa circ_0005986 inhibits carcinogenesis by acting as a miR-129-5p sponge and is used as a novel biomarker for hepatocellular carcinoma. Oncotarget 8: 43878-43888, 2017.

41. Yu L, Gong X, Sun L, Zhou Q, Lu B and Zhu L: The circular RNA Cdrlas act as an oncogene in hepatocellular carcinoma through targeting miR-7 expression. PLoS One 11: e0158347, 2016 .
42. Huang XY, Huang ZL, Xu YH, Zheng Q, Chen Z, Song W, Zhou J, Tang ZY and Huang XY: Comprehensive circular RNA profiling reveals the regulatory role of the circRNA-100338/miR-141-3p pathway in hepatitis B-related hepatocellular carcinoma. Sci Rep 7: 5428, 2017.

43. Wang BG, Li JS, Liu YF and Xu Q: MicroRNA-200b suppresses the invasion and migration of hepatocellular carcinoma by downregulating RhoA and circRNA_000839. Tumour Biol 39: $1010428317719577,2017$.

44. Huang G, Zhu H, Shi Y, Wu W, Cai H and Chen X: cir-ITCH plays an inhibitory role in colorectal cancer by regulating the Wnt/beta-catenin pathway. PloS One 10: e0131225, 2015.

45. Zhang XL, Xu LL and Wang F: Hsa_circ_0020397 regulates colorectal cancer cell viability, apoptosis and invasion by promoting the expression of the miR-138 targets TERT and PD-L1. Cell Biol Int 41: 1056-1064, 2017.

46. Xie H, Ren X, Xin S, Lan X, Lu G, Lin Y, Yang S, Zeng Z, Liao W, Ding YQ and Liang L: Emerging roles of circRNA 001569 targeting miR-145 in the proliferation and invasion of colorectal cancer. Oncotarget 7: 26680-26691, 2016.

47. Hsiao KY, Lin YC, Gupta SK, Chang N, Yen L, Sun HS and Tsai SJ: Noncoding effects of circular RNA CCDC66 promote colon cancer growth and metastasis. Cancer Res 77: 2339-2350, 2017.

48. Zhu X, Wang X, Wei S, Chen Y, Chen Y, Fan X, Han S and Wu G: hsa_circ_0013958: A circular RNA and potential novel biomarker for Lung adenocarcinoma. FEBS J 284: 2170-2182, 2017.

49. Wan L, Zhang L, Fan K, Cheng ZX, Sun QC and Wang JJ: Circular RNA-ITCH suppresses lung cancer proliferation via inhibiting the Wnt/ $\beta$-catenin pathway. Biomed Res Int 2016: 1579490,2016

50. Chen L, Zhang S, Wu J, Cui J, Zhong L, Zeng L and Ge S: CircRNA_100290 plays a role in oral cancer by functioning as a sponge of the miR-29 family. Oncogene 36: 4551-4561, 2017.

51. Zheng J, Liu X, Xue Y, Gong W, Ma J, Xi Z, Que Z and Liu Y: TTBK 2 circular RNA promotes glioma malignancy by regulating miR-217/HNF1ß/Derlin-1 pathway. J Hematol Oncol 10: 52, 2017.

52. Peng N, Shi L, Zhang Q, Hu Y, Wang N and Ye H: Microarray profiling of circular RNAs in human papillary thyroid carcinoma. PloS One 12: e0170287, 2017.

53. Wang K, Sun Y, Tao W, Fei X and Chang C: Androgen receptor (AR) promotes clear cell renal cell carcinoma (ccRCC) migration and invasion via altering the circHIAT1/miR-195-5p/29a-3p/29c-3p/CDC42 signals. Cancer Lett 394: 1-12, 2017.

54. Li F, Zhang L, Li W, Deng J, Zheng J, An M, Lu J and Zhou Y: Circular RNA ITCH has inhibitory effect on ESCC by suppressing the Wnt/ $\beta$-catenin pathway. Oncotarget 6: 6001-6013, 2015.

55. Wang Y and Wang Z: Efficient backsplicing produces translatable circular mRNAs. RNA 21: 172-179, 2015.

56. Yang Y, Fan X, Mao M, Song X, Wu P, Zhang Y, Jin Y, Yang Y, Chen LL, Wang Y, et al: Extensive translation of circular RNAs driven by N6-methyladenosine. Cell Res 27: 626-641, 2017.

57. Yang Y, Gao X, Zhang M, Yan S, Sun C, Xiao F, Huang N, Yang $X$ and Zhao K, Novel role of FBXW7 circular RNA in repressing glioma tumorigenesis. J Natl Cancer Inst 110: 2018.

58. Du WW, Yang W, Liu E, Yang Z, Dhaliwal P and Yang BB: Foxo3 circular RNA retards cell cycle progression via forming ternary complexes with p21 and CDK2. Nucleic Acids Res 44: 2846-2858, 2016.

59. Du WW, Fang L, Yang W, Wu N, Awan FM, Yang Z and Yang BB: Induction of tumor apoptosis through a circular RNA enhancing Foxo3 activity. Cell Death Differ 24: 357-370, 2017.

60. Xia W, Qiu M, Chen R, Wang S, Leng X, Wang J, Xu Y, Hu J, Dong G, Xu PL and Yin R: Circular RNA has_circ_0067934 is upregulated in esophageal squamous cell carcinoma and promoted proliferation. Sci Rep 6: 35576, 2016

61. Yang P, Qiu Z, Jiang Y, Dong L, Yang W, Gu C, Li G and Zhu Y: Silencing of cZNF292 circular RNA suppresses human glioma tube formation via the Wnt/ $\beta$-catenin signaling pathway. Oncotarget 7: 63449-63455, 2016.

62. Yang Q, Du WW, Wu N, Yang W, Awan FM, Fang L, Ma J, Li X, Zeng Y, Yang Z, et al: A circular RNA promotes tumorigenesis by inducing c-myc nuclear translocation. Cell Death Differ 24: 1609-1620, 2017.

63. Zhu M, Xu Y, Chen Y and Yan F: Circular BANP, an upregulated circular RNA that modulates cell proliferation in colorectal cancer. Biomed Pharmacother 88: 138-144, 2017. 
64. Li P, Chen H, Chen S, Mo X, Li T, Xiao B, Yu R and Guo J: Circular RNA 0000096 affects cell growth and migration in gastric cancer. Br J Cancer 116: 626-633, 2017.

65. Yao Z, Luo J, Hu K, Lin J, Huang H, Wang Q, Zhang P, Xiong Z, He C, Huang Z, et al: ZKSCAN1 gene and its related circula RNA (circZKSCAN1) both inhibit hepatocellular carcinoma cell growth, migration, and invasion but through different signaling pathways. Mol Oncol 11: 422-437, 2017.

66. Huang M, He YR, Liang LC, Huang Q and Zhu ZQ: Circular RNA hsa_circ 0000745 may serve as a diagnostic marker for gastric cancer. World J Gastroenterol 23: 6330-6338, 2017.

67. Li WH, Song YC, Zhang H, Zhou ZJ, Xie X, Zeng QN, Guo K, Wang T, Xia P and Chang DM: Decreased expression of Hsa circ_00001649 in gastric cancer and its clinical significance. Dis Markers 2017: 4587698, 2017.

68. Chen S, Li T, Zhao Q, Xiao B and Guo J: Using circular RNA hsa_circ_0000190 as a new biomarker in the diagnosis of gastric cancer. Clin Chim Acta 466: 167-171, 2017.

69. Fu L, Yao T, Chen Q, Mo X, Hu Y and Guo J: Screening differential circular RNA expression profiles reveals hsa_circ_0004018 is associated with hepatocellular carcinoma. Oncotarget 8: 58405-58416, 2017.

70. Shang X, Li G, Liu H, Li T, Liu J, Zhao Q and Wang C: Comprehensive circular RNA profiling reveals that hsa circ 0005075, a new circular RNA biomarker, is involved in hepatocellular crcinoma development. Medicine (Baltimore) 95: e3811, 2016.
71. Xu L, Zhang M, Zheng X, Yi P, Lan $\mathrm{C}$ and $\mathrm{Xu} \mathrm{M}$ : The circular RNA ciRS-7 (Cdrlas) acts as a risk factor of hepatic microvascular invasion in hepatocellular carcinoma. J Cancer Res Clin Oncol 143: 17-27, 2017.

72. Qin M, Liu G, Huo X, Tao X, Sun X, Ge Z, Yang J, Fan J, Liu L and Qin W: Hsa_circ_0001649: A circular RNA and potential novel biomarker for hepatocellular carcinoma. Cancer Biomark 16: 161-169, 2016.

73. Zhang P, Zuo Z, Shang W, Wu A, Bi R, Wu J, Li S, Sun X and Jiang L: Identification of differentially expressed circular RNAs in human colorectal cancer. Tumour 39: 1010428317694546 , 2017.

74. Li W, Zhong C, Jiao J, Li P, Cui B, Ji C and Ma D: Characterization of hsa_circ_0004277 as a new biomarker for acute myeloid leukemia via circular RNA profile and bioinformatics analysis. Int J Mol Sci 18: E597, 2017.

75. Lu L, Sun J, Shi P, Kong W, Xu K, He B, Zhang S and Wang J: Identification of circular RNAs as a promising new class of diagnostic biomarkers for human breast cancer. Oncotarget 8: 44096-44107, 2017.

76. Lu R, Shao Y, Ye G, Xiao B and Guo J: Low expression of hsa_circ_0006633 in human gastric cancer and its clinical significances. Tumour Biol 39: 1010428317704175, 2017.

77. Fang Y, Ma M, Wang J, Liu X and Wang Y: Circular RNAs play an important role in late-stage gastric cancer: Circular RNA expression profiles and bioinformatics analyses. Tumour Biol 39: $1010428317705850,2017$. 